\title{
Should children have best friends?
}

\author{
Mary Healy \\ University of Roehampton \\ Grove House 123 | Froebel College \\ University of Roehampton | London | SW15 5PJ \\ Mary.Healy@roehampton.ac.uk | www.roehampton.ac.uk \\ Tel: +44 (0) 2083928165
}

\begin{abstract}
An important theme in the philosophy of education community in recent years has been the way in which philosophy can be brought to illuminate and evaluate research findings from the landscape of policy and practice. Undoubtedly, some of these practices can be based on spurious evidence, yet have mostly been left unchallenged in both philosophical and educational circles. One of the newer practices creeping into schools is that of 'No best friend' policies. In some schools, this is interpreted as suggesting that children should not have just one best friend but a group of good friends. In others, it is interpreted as suggesting that children should forgo having best friends altogether and be friends with everyone. What is common to both is that friendship is seen as somehow 'dangerous'.

This article offers a preliminary examination of what has been referred to as this 'dark side' of friendship. Whilst philosophers such as Patricia White have previously alluded to its existence, there has been little philosophical scrutiny in any broad terms elsewhere. I examine three common arguments commonly used to justify 'No best friends' practices: that children can be friends with everyone; that young children are developmentally incapable of 'real' friendship hence best friendship should be avoided until later age; that only good people can be good friends. I indicate why this unreflective adoption of practices matters so much and why we should be prepared to challenge these cases. I identify practices that we have good evidence to support as making a positive difference in this area.
\end{abstract}

\section{Key words}

'No best friends'; friendship and morality; rejection and ostracism; pupil well-being; policy 


\section{Should children have best friends?}

The head teacher of a private day school in London was reported in the press in 2013 to have advised that young children should not be encouraged to have 'best friends', but to have lots of 'good friends' instead. He claimed that having best friends made children vulnerable to hurt and loneliness if rejected, to conflict or bullying caused by 'fallings out' between friends or even to ostracism for some. The head teacher argued that young children were less able to deal with such problems hence 'best friendship' might be better left until an older age when children were more able to cope. ${ }^{1}$

Over the past few decades, there has been an unprecedented level of pressure on schools to improve standards from governments of all political persuasions across the globe. These demands for continuous improvement have undoubtedly created the background against which schools focus on everything that may impact on a child's learning. Even pupil relationships have come under the microscope (for example Day 1996) and been seen as a possible site of 'disruption' that impact on learning. Two arguments are usually voiced: first, that teachers dealing with the ensuing problems of pupil relationship problems ${ }^{2}$ in the classroom are being distracted from their primary aim of teaching. Secondly, stable, successful peer relationships can be associated with higher school performance (for example, Ladd 1990).

Under such pressures to 'improve', schools might be tempted to reach out to programmes or policies that claim to raise achievements albeit by less conventional means. Some inevitably fall prey to the many companies that promise 'quick fixes'. The growth of some of these practices has mostly been left unchallenged in both philosophical and educational circles, enabling them to spread and flourish without

\footnotetext{
${ }^{1}$ http://www.telegraph.co.uk/education/educationnews/10031299/Children-shouldnt-have-best-friends-privateschool-head-argues.html http://www.bbc.co.uk/news/magazine-22383453

http://www.bbc.co.uk/newsround/30097068 - example from Denmark reported $19^{\text {th }}$ November 2014

${ }^{2}$ Despite the copious evidence proving the 'benefits' of friendship, victimisation, bullying and malicious gossip amongst friends are all well researched areas.
} 
hindrance. ${ }^{3}$ Admittedly, most schools tend to adopt 'best practices' based on 'what works' in other schools or promoted in local head teacher meetings; some of these practices are backed up by empirical evidence demonstrating their efficacy, but others can give rise to serious misgivings. As Winstanley points out, the careful 'cherry-picking' of policies does not always travel well across differing contexts (Winstanley 2012); at the local or regional level, this can be equally problematic.

One of the newer practices creeping into UK primary schools is that of 'No best friends'. In some schools, the practice is interpreted as suggesting that children should not have just one best friend but a group of good friends (the intention being to avoid dependence on just one other person for one's happiness and to lessen the effects of cliques and bullying). In others, it is interpreted as suggesting that children should forgo having best friends altogether and be friends with everyone. What is particularly of interest about this practice is that it has attracted considerable news coverage in recent years, and not always positive. Most readers of such news reports as this article started with tend to react in similar ways: it may result in a mild bemusement as to how he (the head teacher) proposes to enforce this. This may be followed by simply dismissing the case as deserving further thought, assessing the head teacher as mixing up the concepts of friendship and friendliness or general social skills. For others, there may be a mild curiosity as to why best friendship should be viewed as being so dangerous as to elicit the opinion that it should be discouraged or subject to age limits.

When it comes to friendship, few concepts are as linked to our sense of personal well-being yet, at the same time, as frequently taken for granted. Research

\footnotetext{
${ }^{3}$ To avoid possible confusion between policy (governmental level) and school based policies (procedures relating to the day-to-day implementation of practices), I will refer to the school based as 'practices'.
} 
has increasingly linked our ability to lead a happier and healthier life to the quality and quantity of our friendships (see Barker 2002; Buote et al. 2007). So it is difficult to immediately see why it should so often occupy a precarious position in the values espoused by schools. For many schools, friendship tends to be something schools have to 'work around' or is viewed as a site of possible disruption, whereas for young children, school is often viewed as the place where they get to see and play with their friends - particularly their 'best friends'. Teachers may express misgivings about letting friends sit together or to work together for fear of disruption in the classroom and/or lack of focus on the learning task. Others voice misgivings that children will overly favour their friends in some way, to the detriment of other classmates. Such views have often led to school practices ranging from deliberately separating friends in the classroom to the splitting of friendship groups between parallel classes.

The temptation may be to think that, whilst this may be interesting for those teachers of young children, it may not be that important a topic for philosophy of education itself. This would be a mistake: I want to suggest the implications go far beyond whether or not children should be encouraged to have best friends (which may turn out to be largely an empirical claim) in that it causes us to think about how we treat those outside our closest relationships, an important factor in our moral thinking and thus an important issue for schools. Similarly, it raises important questions as to the basis for practices adopted for performance measurement and management which, when examined, may lack coherence with our commitments in other important areas.

Philosophy of education has long played an important role in educational scholarship, making a significant contribution in how we frame and analyse educational problems. An important theme in the philosophy of education community 
in recent years has been the way in which philosophy can be brought to illuminate and evaluate research findings from the landscape of policy and practice (White 2012). Whilst much of this has centred on the political policy arena, I argue that it is equally as critical for philosophers of education to contribute to well-considered policy and practice decisions at practitioner level.

This article offers a preliminary examination of what tends to be referred to as the 'dark side' of friendship. Whilst philosophers such as Patricia White have previously alluded to its existence (White 1990), there has been little philosophical scrutiny in any broad terms elsewhere. To do this, I first clarify the concept of friendship itself. I then argue that the head teacher is correct to be worried about the problems he cites: that children can be friends with everyone; that young children are developmentally incapable of 'real' friendship hence best friendship should be avoided until later age; that only good people can be good friends. Following this, I indicate why this unreflective adoption of misconceived practices matters so much and why we should be prepared to challenge these cases. Finally, I identify practices that we have good evidence to support as making a positive difference in this area.

\section{What is friendship?}

A plethora of literature studying friendship from both empirical and theoretical perspectives has traditionally focussed on either the perceived link with moral development, or on the development of intimate relationships or on links to our personal well-being (see the work of Selman 1980; Blum 1980; Buhrmester 1990). All of this has led to the general agreement (crossing multiple disciplines) that friendship is both advantageous and desirable for both parties. Within the philosophical domain, the concept of 'friend' (philia) used in many of the Greek 
exemplars on friendship is widely acknowledged to cover a multitude of areas, from those relationships of many years, to familial relationships and to those of civic relationships (Cooper 1991). Aristotle, from whose work much of this literature has developed, purports that intimate relationships are a necessary part of the flourishing life (Aristotle NE 1155a5).

Anthropologists suggest that friendship is typically the first significant relationship outside of family ties to develop (Bell and Coleman 1999). However, it is important to remember that not all social relationships are ones of friendship. Researchers such as Pahl remind us that the term 'friend' is used to cover a wide variety of social interactions from informal relationships, the connectedness of social networks, companionship playmates to the quasi-kinship relationships of close friendship (Pahl 2000) as well as the ubiquitous 'friending' of virtual social networks. In other words, friendships, good peer relationships and general 'pro-social skills' are all different spheres of engagement. As children now spend the major part of their day outside of the family, often in the company of other children (e.g. in schools, play groups, child-minding situations, activity groups such as clubs or sports) their ability to understand and negotiate their rapidly developing social world in different contexts can be a key contributor to their future development and well-being. But what is it about friendship that makes it so distinctive?

The first point to make is that one cannot be a friend in isolation: it requires the existence of another person. Whilst we have the concept of unrequited love for situations where the love is unreturned, this does not hold for friendship. The affection and support we associate with friendship excludes a one-sided relationship: it must be mutual. Secondly, friendship requires something of both parties - the being friendly, a liking or loving emotional involvement, a 'being a friend' in wanting 
and actively trying to benefit the other, a wishing for their good, and an involvement in some mutually-acceptable way in each others' lives. Thirdly, to call someone a friend is to see him or her as being special, thus to set someone apart from those who are 'not friends'. The implication here is that we behave, feel and act differently towards our friends than our non-friends; the presumption is that it should have at least some implications for behaviour by ruling in (or out) particular ways of acting. Given that friends may occupy a different place in our thinking to non-friends, we can only expect that best friends will be a further distinctive (and even more exclusive) grouping than the category of friends. Children thus have recourse to a wide variety of relationships: peer relationships (usually referred to as general pro-social skills or being 'sociable' with those of a similar age), friends (a smaller subgroup they may choose and enjoy the company of - 'friendliness') and best friends (an even smaller subgroup of a deeper, long-term, more exclusive relationship based on mutual affection and support).

A further point to make is that there is a temporal aspect to friendship: it is not possible to decide to be friends with someone - and then suddenly to be so. It takes time to build the friendship: exploring each other's character, tastes, likes, dislikes, opinions etc. This type of engagement and the depth of knowledge of the other can only be experienced with a few and not with everyone we encounter: none of our lives are long enough to devote the amount of time it would require. Thus the expectation of children to be 'friends with everyone' (as opposed to being sociable or friendly), would be unachievable, even if held to be desirable. In summary, friendship has to be understood as being more than just general socialisation skills. 


\section{First claim: The dark side of friendship}

The philosophical significance of this particular school practice hinges on the question of whether or not the evidence confirms 'the dark side' of friendship, or at the very least, suggests its existence may be plausible. So what exactly does the head teacher see as being dangerous? To answer this, we first need to recognise that all friendships create boundaries: they indicate those who are friends and equally those outside of the friendship. By calling someone a friend we are denoting a particular status to him or her in our thinking that sets him or her apart from those who do not share that status. We are not restricted to having just one friend neither does having a friend preclude that person from being someone else's friend as well but each pairing will be different.

Most of us are enmeshed in a variety of different, complex friendship networks which may be at varying levels of intimacy and attachment. But when it comes to 'best friendship', we can refer to 'the best kind' of friendship or 'the best people' or simply 'those we choose to be closest to'. There is something even more 'special' about these friendships than others, hence the sheer volume of literature trying to identify what this might consist of (Blum 1993; Helm 2010; Nehamas 2010). The trust may be deeper, the mutual affection more intense, our inclination to protect or support may be more multi-layered; this can make the boundaries of those inside (and thus those left outside) appear tighter and more rigid. In all of these cases the relationship is perhaps most akin to the depth of attachment (and subsequent virtues) depicted by Aristotle as virtue friendship (Aristotle NE) or by Cocking and Kennett as companionate friendship (Cocking and Kennett 1998). We must remember, however, that it is not friendship per se that the head teacher found troubling, but 'best friendship' springing from the exclusivity problems associated 
with the relationship. Indeed, many of the charges laid by the head teacher focus specifically on those left outside the boundaries of such relationships. So let's look more closely at the evidence for this.

Rejection: Conceptually, to be rejected as a friend suggests one has to have first offered or been available for friendship and then to have the offer turned down or ignored (whether consciously or unconsciously). ${ }^{4}$ In a similar vein, the 'rejected' child might be one who occupies the role of 'substitute friend' - someone who is a 'temporary friend' in the absence of the real friend - and who is then dropped on the return of the desired other. All children undoubtedly have experiences that could be termed rejection in some form, whether in the shape of peer teasing, the momentary absence of a playmate or the more serious forms of bullying and exclusion (which demonstrate extreme forms of rejection). Whilst many children seem to negotiate their way through these events relatively easily, others can be caught in a seeming downward spiral of 'rejection', especially if they experience rejection across many domains (school, neighbourhood, home etc).

Research even seems to suggest that being 'peer-rejected' can be fairly regular in occurrence for some groups of children. Mikami et al, for example, claim that around half of children rejected at any given time will also suffer rejection at a further date (Mikami et al. 2005). This continual experience of rejection as a 'possible friend' has been associated with an increased emotional/social vulnerability, with being more likely to drop out of school, with engagement in criminality or with suffering from anxiety and depression in later life (Sandstrom 2004).

\footnotetext{
${ }^{4}$ Just as one can deliberately reject another, it is possible to reject another without intending or realising that that is the effect of the behaviours.
} 
Ostracism: Ostracism, on the other hand, goes far beyond peer-rejection to encompass behaviours that communicate dislike of a child in perhaps a more nonconfrontational manner. This is often demonstrated by restricting access to joint enterprises, by chronic peer exclusion and social isolation. In extreme cases, this may degenerate into viewing the other as an 'enemy', or by deliberately sabotaging work or equipment, often at school itself. Normally, being accepted as a member of a group of friends means being included within the system of everyday reciprocities within that 'community', hence being denied access through ostracism is to see and treat another as 'undeserving' of access to mutual benefits. Here the boundary signifies the negation of any duties or responsibilities at all towards those outside of the bond.

There can be few things as emotionally damaging for a young child as being made to feel they neither matter nor belong. This form of chronic victimisation of students by their peers (ostracism) goes beyond just emotional damage (serious as this is), to severely affecting the child's academic learning. We know from research that in being denied engagement in class activities, poor academic achievement in later years becomes much more likely for this group (Hawes et al. 2012).

Loneliness: For children, loneliness (when seen as the outcome of friendlessness) can be considered to be one of the most miserable experiences of childhood (White 1990). Being the only one without a playmate whilst all around you are paired off or in ready-set groups, being always left out of games at playtime (not as ostracised but as being the 'invisible' child) has long been argued to undermine both the confidence and social competence of children across domains (from increased social anxiety, to low self-esteem, to hyper-sensitivity and depression). Some children undoubtedly take longer to develop 'best friendship' than others or may indeed feel 'left out' 
amongst their peers who might have strong established social groups. Obviously, there is a difference between being alone and being lonely: most of us will relish being alone at least sometimes. But to be alone all of the time, when one desires closeness and interdependency with others, can serve to make school life unbearable for some.

Surely any person involved in the education of children would rightly be concerned about such possible outcomes of these problems? Now, we may be tempted to rethink our initial response to the head-teacher, and consider that perhaps he might be on to something. But these negative side effects are not problems of 'best friendship' per se. Indeed, these tribulations are just as likely to result from all friendships as from best friendships. ${ }^{5}$ Similarly, there is copious research to suggest that in such situations as described previously, close (or best) friendships may serve as a protective support or comfort - even having just one relationship may act as a social buffer against peer rejection.

Part of the problem is undoubtedly that friendship and being friendly have been set up as an 'either/or' choice in his argument: you can either have a few good friends (risking the hurt and difficulties in negotiating friendship) or you can be friends with everyone (an impossibility in the same depth - and probably more typically, being friendly). But the choice between the two is a false one: children need to develop both sets of skills, aptitudes and attachments. Similarly, we need to be careful not to draw unwarranted conclusions from empirical concerns over peer victimisation: this may occur whether or not a child has a best friend.

\footnotetext{
${ }^{5} \mathrm{I}$ am indebted to the feedback from one of the reviewers on this point.
} 
So is there a problem in best friendship itself? What exactly is it that proponents of such policies object to? The basic argument seems to be that in best friendship, the pain of abandonment is deeper, the betrayal of trust is more intense, than in other network or peer relationships: a variation on the ones we love the most, hurt us the most'. Friendships may make us vulnerable to hurt, but they are also capable of giving us great joy and make life worth living. This vulnerability is found in all human relationships - by giving them value, we are inevitably opening up to the possibility of hurt if they go wrong. But learning to deal with the emotions of loss and pain is also part of our social development and attempts to shield children from this could be detrimental.

What we can conclude, however, is that examining the practice without any reference to the concepts disconnects the educational ideas from the philosophical and theoretical structures of which they are an integral part. The conceptual laxity underpinning the 'no best friends' practice, and the subsequent failure of proponents of such practices to take account of the philosophical issues inherent in this area, then suggests an impoverishment of evaluative criteria by which to judge the legitimacy of such claims by those charged with articulating this in schools.

\section{Second claim: The development of friendship}

All schooling to some extent involves socialisation (in the sense of learning to be both in the world and with others) and popular theories of child development have long acknowledged the powerful influence that friendship plays in the social and moral life of the child (Piaget 1932/1965; Kohlberg 1981). Indeed, 'achieving friendship' is often seen as a major goal for many preschool and early school settings: that is, encouraging children to be social, friendly, polite and empathetic to others' feelings. 
Here, I want to make two points. First, many of these theories can be classified as 'stage theories' in that they ascribe particular characteristics to particular age groups. Often based on the cognitive developmental approach adopted by Robert Selman (Selman 1980), many studies concentrate on changes in social perspective-taking and intimacy to account for an individual's increasingly complex interactions in the social world. But suggesting that children should be denied the pleasures of particular friendships whilst young because they are less able to deal with the emotional problems brought on by conflict and less capable to negotiate through the intricacies of social relationships, seems to be misinterpreting the basis for social development and to suggest some unspoken 'hazy' form of 'friendship-readiness'.

Undoubtedly, as biological entities, we change and grow through time. Some of those changes are related to the stage of our biological development: the ability to eat and digest solid food; the ability to reproduce. Others may be the results of both biology and social conditions (for example, the development of shared language). Others, still, depend on our ability to build on our past experiences to understand and negotiate our present and future experiences. Saying that children around a particular age are more 'capable' of best friendship may simply indicate that the cumulative effect of the experiences they have previously had, the joys and the disappointments, the experiences of trusting, being betrayed or abandoned, mean they have more to draw on when coping with the present problems in relationships. The development of many of the features of best friendship such as deep trust, the development of intimacy, of love and affection, of tolerance, of reciprocal actions, all these take time and opportunities to develop in real relationships. Being discouraged 
from forming best friendships, or denied the opportunity to nurture these until a particular age then seems somehow incoherent as a response.

The second point to make is that a deeper reading of the empirical literature suggests that having a close friendship (or best friendship) may be a key site of support which can be particularly important in alleviating the psychological stress and adjustment difficulties associated with major changes (Brooks 2007; Buote et al. 2007; Kingery et al. 2011). In other words, 'best friendship' has a special utility value in supporting those undergoing these critical periods of stress. This achieves particular pertinence within the realm of schooling in that 'transitioning' pupils/students are known to make transitions more easily when they can access the support from close relationships such as friends. As children commonly go through many transitions (whether between schools, key stages, or even changes of class and teacher in primary schools), it would seem reasonable to suppose that doing so with the help of another would make the process easier. Indeed Kingery et al posit that "adolescents who do not have a strong social network (e.g., fewer friends, lowerquality friendships) in late elementary school may not have a secure base to rely upon when navigating the transition" (Kingery et al. 2011, 218). This would suggest that, if only on instrumental grounds, schools may be better off encouraging the development of 'best friendship' rather than forbidding it.

\section{Third claim: friendship and morality revisited}

Implicit in the head teacher's view is the belief that 'best friendship' puts children in some form of danger. What is particularly curious however, in our example, is the head teacher's association of best friendship with vices towards others when, generally speaking, deep friendship is usually associated with virtue and/or moral 
behaviour. This association with virtue has a long distinguished history: psychologists such as William Damon argue that the ability to place oneself in the position of another, being able to see oneself as separate, is key to moral development (Damon 1977).

At a simple level, the key belief here is that friendship opens us up to the moral life in particular ways, by providing the motivation to sacrifice some of our own interests for the sake of the loved friend. Much of this thinking can be traced back to the Aristotelian view that friendship is a particular way through which we can achieve eudemonia: friendship "is a virtue or involves virtue; and it is an absolute necessity in life" (Aristotle NE, VIII.I). The philosophical tradition of limiting true friendship ${ }^{6}$ "to the morally virtuous" (Nehamas 2010, 274), that has come to be drawn from the Aristotelian typology of utility, pleasure or virtue friendships ${ }^{7}$, has more or less continued in various guises in much of the literature.

Few of us could realistically reach the level of being completely virtuous, so it would seem at first to suggest that most of us could never experience this type of friendship. John Cooper, however, challenges this interpretation and suggests a more realistic view, arguing that Aristotle's vision of perfect virtue is better placed within a wide spectrum of virtue friendships, hence an individual would not need to show every kind of virtue, but only need some good qualities to attract and hold a possible friend (Cooper 1977). Whilst this leaves open the opportunity of developing virtue friendships to those of us who are not complete paragons, it is clear the link is still retained (albeit weaker) between moral virtue and friendship.

This argument was recently revisited by Elder (Elder 2014), who argues for a much more eudaemonist view on friendship reaffirming the view that the best friends

\footnotetext{
${ }^{6}$ Generally seen as the 'best kind' or most desirable type of friendship

${ }^{7}$ Utility and pleasure friendships are frequently regarded as lesser or incomplete forms of friendship, with virtue (sometimes called character or perfect friendship) regarded as the highest or most complete form.
} 
must be good people. Elder argues that "the best friendships are those between friends who share at least some important values. Shared values promote closeness, which is central to friendship" (Elder 2014, 95). He reminds us that for the Aristotelian, character matters to one's well-being and that virtue plays an important part in the best lives. However, a morally virtuous person would act in a morally virtuous way in not only one situation, but also in another: there would have to be consistency of action. In other words, a person who exhibited the virtues solely with their best friend, but was vicious, unkind and unethical with others, could not possibly be described as 'morally virtuous'. Hence, the development of the virtues between best friends does not preclude our acting morally to those outside the bond - if anything it suggests that to be truly virtuous, the moral boundaries have to expand beyond the friendship.

But Elder goes further than this to assert that it is in the best interest of good people not to choose bad people as their friends as this could lead to the possible corruption of the virtuous. ${ }^{8}$ Elder asserts that being close to the wrong individuals can deprive persons of at least some of the virtues needed to live a good life, as they cannot be relied on to consistently promote each other's good. ${ }^{9}$ There are three related responses to be made here. First, as Jeske points out, we often begin interacting with someone before we can ascertain his or her character, before we come to know all the good or weak character traits of the person (Jeske 1997). In

\footnotetext{
${ }^{8}$ Such a stance, if realised in schools, risks being misinterpreted as suggesting that some children should not be chosen as friends or are undeserving of friendship.

${ }_{9}$ Elder gives the example of gamblers, who, he argues, may share a common interest and be directly sensitive to each others' interests in gambling, and who, inadvertently, are helping each other to hurt themselves. However, it seems to me that it is possible that the two gamblers can be 'best friends' or 'good friends' to each other without that friendship being 'the best possible friendship' they could choose (using Cooper's spectrum argument). This is not just a semantic point: it at least partially undermines Elder's argument that 'bad people' cannot be good friends.
} 
fact, we may come to care about them, despite their failures or weaknesses and yet still have good reason to remain in the friendship.

Secondly, such an argument appears to suggest a particularly ego-centric view of the self, acting to one's own advantage which would then itself lack the 'othercenteredness' seen as critical to virtue friendship. Yet Aristotle (on whom Elder bases much of his argument) clearly does not expect the virtuous to drop their 'corrupted' friends as a first resort. The expectation is that the virtuous person, because of their virtue, would try to reform their friend and return them to their original position - only if they prove irredeemable, should the friendship be avoided.

Thirdly, just as friends can be attracted to one another on the basis of virtue and admirable qualities, they can also be attracted on the basis of vices and "weaknesses of character" (White 1990, 84). It is not unknown for children to form friendships that 'bring out the worst in them' (partners in crime) rather than the best. Indeed, most teachers will have memories of teaching children who seemed to be drawn together by shared engagement in less admirable activities. It is perfectly possible that two friends may be 'good' to each other: thoughtful, supportive, affectionate - but their behaviour to others outside of the friendship can be thoughtless, unaccommodating and downright cruel. ${ }^{10}$

It would seem somewhat contrary to experience to argue, as Elder does, that those involved in such behaviour cannot be classified as 'good friends' at all because the result or outcome of their relationship is harmful to others (or even to themselves) in some way. Even 'bad' people can have (and be) good friends to

\footnotetext{
${ }^{10} \mathrm{I}$ am thinking in particular of actions such as group bullying. Research on aggressive behaviour (such as bullying in schools) has often demonstrated that this can be often a group process in which children can reinforce each other through the shared behaviour (see: Salmivalli 1999). Similarly, it is possible for a Nazi soldier to be a good friend with other Nazis whilst being monstrous to those judged by their belief system to be outside and undeserving of common humanity. It should also be born in mind that relational 'disorders' such as folie a deux, cult memberships, perhaps even gang or terrorist groupings, can also show some features of close friendship to each other.
} 
some. Similarly we cannot assume that the outcome of all good friendships will be virtuous: friendship can not only be expressed through good deeds, but "can be expressed even through crime, cruelty and immorality" (Nehamas 2010, 276-7). If, as Cooper argues, virtue friendship is better seen as part of a wide spectrum, perhaps 'vice friendships' might also form part of this spectrum.

\section{What can schools do?}

So why should this small, seemingly insignificant policy be taken so seriously by academics? I want to suggest four interrelated reasons: first, it matters that schools adopt policies based on real evidence. We know that children who develop best friendships tend to live happier and healthier lives (Gutman and Feinstein 2008). We know that children with deep friendships cope better with stress (Berndt and Keefe 1995). We know that children with best friends tend to transition between stages with greater ease (Kingery et al. 2011). We know that as children become adolescents, their friendships become increasingly important to them in developing healthy selfesteem (Hartup 1989; Keefe and Berndt 1996). So we have very good reasons to think that friendship is something policy-makers and schools should pay close attention to. But the unreflective adoption of some policies suggests a need for those in middle and senior management positions to further develop their critical evaluation skills, to give them a better-grounded understanding of what will better improve their practice. This is, admittedly, no easy matter to achieve. It is here, I want to suggest, that philosophy of education, having the unique ability to cross the disciplines of both philosophy and education, has a distinctive role to play. Given that most schools lack adequate access to the rigorous research needed to judge such practices, the task for the philosopher in such circumstances is often to provide a clearer view of the 
commonplace assumptions and to assess the coherence with other commitments we may have.

Secondly, it matters that children are happy in their relationships and develop healthy, positive friendships. Friendship has an enduring impact which affects future development; positive relationships with others are repeatedly stressed as being significant indicators of personal well-being and as a key landmark in a child's psychological and social development (Gutman and Feinstein 2008). Indeed, the evidence points to children with positive friendships having better mental health than those who do not (Ueno 2005). ${ }^{11}$ This link has not gone entirely unnoticed by policy makers: the Secretary of State for Education in the UK, Nicky Morgan, recently claimed that children's emotional well-being should be a governmental priority. ${ }^{12}$ Yet against this renewed interest at governmental level in such matters, we have a developing dichotomy at school level: the growth of "no best friend" policies suggest that schools may in fact be retreating from their traditional role in the social and moral development of pupils. All the evidence is that schools are critical actors in this area: Dill et al suggest that it is the early intervention and active attempts by teachers to encourage friendships and social inclusion that may be crucial (Dill et al. 2004).

Thirdly, it matters that we carefully consider the possible long-term implications of such policies and attain coherence where possible between policies. Denying children the opportunity to develop best friendships runs the risk of children failing to develop important social skills in later life, the resilience developed through negotiating demands between friends, and most of all, the joy of a close, intimate, supporting friendship. Furthermore, denying children the space within which to

\footnotetext{
${ }^{11}$ Interestingly, Gutman and Feinstein found that more satisfaction with friendship seemed to correlate with higher KS2 English scores, and concluded that having friendships seemed to have particular importance for pupils in disadvantaged school areas.

${ }^{12}$ http://www.thetimes.co.uk/tto/education/article4487859.ece
} 
develop such relationships seems to be an extraordinary (and unjustified) intrusion of the school into the private world of possible personal relationships.

Finally, it matters that we should not imply that some groups of children cannot be good friends or are undeserving of good friends. There is no evidence to support this stance and policies making such an assumption could drive such children into loneliness and isolation amongst their peers, increasing the possible disruption within the classroom. This group of children should be as entitled to help with 'socialisation skills' as a child who is unable to read is to literacy intervention.

As stated at the beginning, I wanted to argue that the head teacher was right to be concerned about the 'dark side' of friendship (when viewed as concern for those outside of the boundaries of friendship) but incorrect in his conclusions. If it was merely to alleviate rejection, ostracism and loneliness, the empirical evidence seems to suggest he may be better off encouraging best friendship to alleviate the sheer misery of these three tribulations. Whilst it would be implausible to offer an account of friendship that excluded the specialness of friendship as counting for nothing in discussions of moral obligations and expectations, these are not the only obligations we may have. I think it is this that the head teacher should be trying to voice: how do we encourage and develop a sense of care, compassion and moral behaviour towards others? How do we expand our moral thinking beyond those we are most drawn to?

But what about the philosophical reasons for taking such policies seriously? Philosophical justifications abound re the value of friendship: from a source of selfknowledge (Cocking and Kennett 1998) to friendship as a moral activity (Blum 1993), from friendship as a form of love (Helm 2010), to friendship as a shared commitment (White 1999). To take just one example: an Aristotelian would argue that friendship 
is a necessary component of the flourishing life and one of the highest of virtues (Aristotle, NE). In other words, one cannot live well without friends. Humans, he claims, are essentially social beings. This is at least in part due to the connection that Aristotle draws between friendship and the pursuit of goodness (being one of the ways through which we both develop and display the virtues) and undoubtedly positions friendship as an ethical ideal. For the Aristotelian, the best kind of friendship (character friendship) goes beyond instrumental value to those who love each other for their own sake. It is not about what they do as about who they are, which no list of features or recounted episodes of helpfulness can fully capture. Thus modern intuitions about friendship voiced merely in terms of instrumental reasons (or as a means to some other end) then risk losing sight of something of great value.

So what should schools do? Undoubtedly the promotion of peer acceptance and the prevention of peer rejection can be time consuming and cumbersome in the classroom, which may partially explain the tendency of some schools to shy away from addressing the issues. But there are things that evidence shows can make a difference. First, school staff should be aware of those children 'at risk' of rejection, ostracism and loneliness and to have a shared agreement for how to address or alleviate such issues. There may indeed be good reasons for some children to be rejected as possible friends by some: perhaps they are someone who has shown themselves to be untrustworthy or domineering in the past; they might be rejected out of fear. This then suggests a role for staff to actively support those individuals who may be struggling with forming or maintaining friendships. ${ }^{13}$

Secondly, if best friendships cause disruption in the classroom, there can undoubtedly be justification for practices such as splitting up particular pairings in

\footnotetext{
${ }^{13}$ A common feature of Nurture groups.
} 
some situations. But we must be clear: the problem is the disruption caused, not the friendship. Patricia White (1990) reminds us that learning to do things with others, sharing games, the general give and take in classroom life teaches us important social skills and this might play a significant role here - our friendliness and network skills. But friendship is more than this: being allowed to (sometimes) do these activities with our best friends can also play a further, crucial role: it allows us to get to know and judge the character of the other; to have good reasons for the deep trust needed in such friendships; it gives us the opportunity to deepen the friendship and to teach young children about the limits of friendship partiality in the relatively safe (and usually monitored) space that schools can supply.

Finally, rejection, ostracism or loneliness can often come with significant tensions and conflicts, all of which can be disruptive to learning in the classroom or for the future emotional and social well-being of the child. But these are not problems directly attributable to 'best friendship', but signs of a failure to develop 'prosocial skills', or of the failure to expand our moral thinking beyond those close to us. We cannot insist someone becomes friends with another but we can, and should, encourage a basic level of civility and moral awareness of the rights and needs of others beyond our best friends.

\section{Bibliography}

Aristotle. The Nicomachean Ethics. Trans. David Ross. 1953 Aufl. The World's Classics. Oxford: Oxford University Press.

Barker, Judith C. 2002. Neighbors, friends, and other nonkin caregivers of community-living dependent elders. The Journal of Gerontology 57B (3):158-167.

Bell, S. and S. Coleman, Eds. (1999). The anthropology of friendship. Oxford, New York, Berg. 
Berndt, Thomas J, and Keunho Keefe. 1995. Friends' influence on adolescents' adjustment to school. Child development 66 (5):1312-1329.

Blum, Laurence. 1993. Friendship as a moral phenomenon. In Friendship: a philosophical reader, ed. Neera Kapur Badhwar, 192-211. Cornell University.

Blum, Lawrence. 1980. Friendship, altruism and morality. London; Boston: Routledge and Kegan Paul.

Brooks, Rachel. 2007. Friends, peers and higher education. British Journal of Sociology of Education 28 (6):693-707.

Buhrmester, Duane. 1990. Intimacy of friendship, interpersonal competence, and adjustment during preadolescence and adolescence. Child Development 61 (4):1101-1111.

Buote, Vanessa M., S. Mark Pancer, Michael W. Pratt, Gerald Adams, Shelly Birnie-Lefcovitch, Janet Polivy, and Maxine Gallander Wintre. 2007. The Importance of Friends : Friendship and Adjustment Among1st-Year University Students. Journal of Adolescent Research 22 (6):665-689.

Cocking, Dean, and Jeanette Kennett. 1998. Friendship and the self. Ethics 108 (3):502-527.

Cooper, John. 1977. Friendship and the good in Aristotle. Philosophical Review LXXXVI (3):290-315.

Cooper, John. 1991. Friendship. In Encyclopaedia of ethics, ed. L Becker, 388-391. New York and London: Garland Publishing Company.

Damon, William. 1977. The social world of the child. San Francisco: Jossey-Bass Publishers.

Day, Julia. 1996. School friendship groups and their impact on learning. Education 3-13 24 (1):51-58.

Dill, Edward J, Eric M Vernberg, Peter Fonagy, Stuart W Twemlow, and Bridget K Gamm. 2004. Negative affect in victimized children: The roles of social withdrawal, peer rejection, and attitudes toward bullying. Journal of abnormal child psychology 32 (2):159-173.

Elder, Alexis. 2014. Why Bad People Can't be Good Friends. Ratio 27 (1):84-99.

Gutman, Leslie, and Leon Feinstein. 2008. Children's Well-Being in Primary School: Pupil and School Effects [Wider Benefits of Learning Research Report No. 25]. Centre for Research on the Wider Benefits of Learning, Institute of Education, University of London.

Hartup, Willard W. 1989. Behavioral manifestations of children's friendships. In Peer relationships in child development, eds. Thomas J. Berndt, and G. W Ladd, 46-70. New York: Wiley.

Hawes, David J, Lisa Zadro, Elian Fink, Rick Richardson, Kathleen O'Moore, Brendan Griffiths, Mark R Dadds, and Kipling D Williams. 2012. The effects of peer ostracism on children's cognitive processes. European Journal of Developmental Psychology 9 (5):599-613. 
Helm, Bennett W. 2010. Love, friendship, and the self: Intimacy, identification, and the social nature of persons. Oxford University Press.

Jeske, Diane. 1997. Friendship, virtue, and impartiality. Philosophy and Phenomenological Research LVII (1):51-72.

Keefe, Keunho, and Thomas J Berndt. 1996. Relations of friendship quality to self-esteem in early adolescence. The Journal of Early Adolescence 16 (1):110-129.

Kingery, Julie Newman, Cynthia A Erdley, and Katherine C Marshall. 2011. Peer acceptance and friendship as predictors of early adolescents' adjustment across the middle school transition. MerrillPalmer Quarterly 57 (3):215-243.

Kohlberg, Laurence. 1981. Essays on moral development. San Francisco: Harper \& Row.

Ladd, Gary W. 1990. Having friends, keeping friends, making friends, and being liked by peers in the classroom: Predictors of children's early school adjustment? Child development:1081-1100.

Mikami, Amori Yee, Margaret A Boucher, and Keith Humphreys. 2005. Prevention of peer rejection through a classroom-level intervention in middle school. Journal of Primary Prevention 26 (1):5-23.

Nehamas, Alexander. 2010. XII-The Good of Friendship. Proceedings of the Aristotelian Society (Hardback).

Pahl, Ray. 2000. On friendship. Oxford, Polity.

Piaget, Jean. 1932/1965. The moral judgement of the child. Trans. M Gabain. New York: Free Press.

Salmivalli, Christina. 1999. Participant role approach to school bullying: Implications for interventions. Journal of adolescence 22 (4):453-459.

Sandstrom, Marlene J. 2004. Pitfalls of the peer world: How children cope with common rejection experiences. Journal of Abnormal Child Psychology 32 (1):67-81.

Selman, Robert. 1980. The growth of interpersonal understanding. New York: Academic Press.

Ueno, Koji. 2005. The effects of friendship networks on adolescent depressive symptoms. Social Science Research 34 (3):484-510.

White, John. 2012. The role of policy in philosophy of education: An argument and an illustration. Journal of Philosophy of Education 46 (4):503-515.

White, Patricia. 1990. Friendship and education. Journal of Philosophy of Education 24 (1):81-92. 
White, Richard. 1999. Friendship and commitment. The Journal of Value Inquiry 33(1): 79-88.

Winstanley, Carrie. 2012. Alluring ideas: cherry picking policy from around the world. Journal of Philosophy of Education 46 (4):516-531. 